\title{
INVESTIGATING BETANIN STABILITY, RELEASE PROFILE AND ANTIOXIDANT ACTIVITY OF ETHYL CELLULOSE MICROPARTICLE CONTAINING BEETROOT (BETA VULGARIS, LINN) EXTRACT
}

\author{
ANITA SUKMAWATI ${ }^{*}$, SETYO NURWAINI ${ }^{1}$, UMI BUDI RAHAYU ${ }^{2}$, APRILIANA P. C. WIDAWAN ${ }^{1}$, ANITA SAFITRI ${ }^{1}$, \\ NOVIA W. N. ASTRIA 1
}

1Faculty of Pharmacy, Universitas Muhammadiyah Surakarta, Sukoharjo, Indonesia, ${ }^{2}$ Faculty of Health Sciences, Universitas Muhammadiyah Surakarta, Sukoharjo, Indonesia

*Email: anita.sukmawati@ums.ac.id

Received: 05 Aug 2021, Revised and Accepted: 30 Sep 2021

ABSTRACT

Objective: The objective of this research is to evaluate the ability of ethyl cellulose (EC) microparticle to protect the beetroot (Beta vulgaris, Linn) active substance. In addition, this research also investigates the effect of polymer concentration during microparticle preparation toward physical characteristics of microparticle, release profile of betanin as well as antioxidant activity of microparticle.

Methods: The microparticle was produced using the emulsification method using various concentrations of EC in the organic phase and beetroot extract as the active substances. The physical characterization was carried out including the imaging of microparticle using scanning electron microscope (SEM), zeta potential and encapsulation efficiency (EE). The stability test for an active substance in microparticle was carried out at temperature $40{ }^{\circ} \mathrm{C}$ for $28 \mathrm{~d}$. The release profile was evaluated using the dissolution method and the antioxidant activity was evaluated using 2,2-diphenyl-1-picrylhydrazyl (DPPH).

Results: The result showed that the EC concentration strongly influenced the physical characteristics and EE of beetroot extract in microparticle. The microparticles also had good protection for betanin during storage. The release of active substance from microparticle following Higuchi kinetic. The highest antioxidant activity was found in the microparticle using EC $20 \%$.

Conclusion: The EC microparticle is the potential to protect the degradation of antioxidant substance from natural product. However, the physical properties, EE, the ability to prevent degradation of active substance, release rate and antioxidant activity, are strongly influenced by the EC polymer concentration during microparticle preparation.

Keywords: Antioxidant, Beta vulgaris, Linn, Ethylcellulose, Microparticle, Release kinetic stability

(C) 2021 The Authors. Published by Innovare Academic Sciences Pvt Ltd. This is an open access article under the CC BY license (https://creativecommons.org/licenses/by/4.0/) DOI: https://dx.doi.org/10.22159/ijap.2021v13i6.42848. Journal homepage: https://innovareacademics.in/journals/index.php/ijap

\section{INTRODUCTION}

The use of natural ingredients as active ingredients in cosmetics is becoming popular, especially in relation to efforts to prevent premature aging of the skin by using antioxidants. Antioxidant properties can be obtained from beetroot (Beta vulgaris, Linn), which contains betanin compounds with an $\mathrm{EC}_{50}$ value of $0.275 \mathrm{mg} / \mathrm{ml}$ [1]. The antioxidant compounds in beetroot is unstable due to changes in temperature, light, heat and changes in $\mathrm{pH}$ [2]. The stability of this active substance can be maintained using microencapsulation or microparticle technology. Microparticle (MP) has the ability to protect the active ingredients from factors that cause damage, such as changes in temperature, humidity, oxygen and microorganisms $[3,4]$.

In the manufacture of microparticles, a matrix is the essential part for the encapsulation process which is expected to protect and control the release of the active substance. Ethylcellulose (EC) is one of the cellulosederived matrices that is often used for biomedical applications since its biocompatibility and has been approved for use by the Food Drug Administration (FDA) [5]. Ethylcellulose (EC) is a polymer that has resistance to temperature changes [6]; therefore it is expected to increase the stability of the active substance encapsulated in it. The EC matrix has the property of being soluble in organic solvents; hence the formation of microparticles using EC is highly dependent on the rate of the evaporation rate of the organic solvent used in the process.

The ability of microparticle (MP) for maintaining the stability of the active substance has been shown in some research. Research conducted by Antigo et al. (2018) proved that beetroot microparticles using maltodextrin and xanthan gum as the matrices had good stability of betanin when stored at room temperature [7]. Another study was also conducted by Torres et al. (2019) revealed that colour of beetroot powder which was formulated into microparticle preparations, had no significant colour difference after
8 w. This study also stated that betanin microencapsulation was considered safe based on the result of microbial testing, heavy metal dan dermal irritation test [8]. The research using the microparticles technique to maintain the active substances of vitamin $C$ has also been carried out by Dong and Wang (2016) using chitosan polymer. Besides being able to increase the stability of the active ingredient of vitamin C, drug release can also be controlled [9]. The stability of vitamin $C$ in microparticless can be maintained at a storage temperature of $45^{\circ} \mathrm{C}$ in a study conducted by Rojas (2015) [10]. The encapsulation technique using particles with an EC matrix has also been shown to prevent thermal oxidation of soybean oil encapsulated in the EC matrix [6]. The encapsulation technique using chitosan as a matrix can be used to maintain the stability of Olmesartan medoxomil for 2 mo as well as improves the properties of the particles [11].

In the microparticles preparation, the concentration of polymer as a microparticle matrix would affect the characteristics of the microparticles, including the encapsulation efficiency (EE), particle size and the release profile of the active ingredient from the matrix. Research by Muhaimin (2013) indicated that the escalation in the concentration of EC as matrix in MP preparation is proportional to the EE of propranolol $\mathrm{HCl}$ in the microparticles [12]. The high concentration of polymer solutions induced the speed of polymer hardening into microparticles; as a consequence, the EE would have the higher value [13]. Increasing the concentration of chitosan matrix in the preparation of microparticles also leading to an increase the size of the particles [14]. However, the increase in particle size is not always linear with the increase in the concentration of chitosan used in the formulation of micro or nanoparticles because it can also be influenced by other materials used in the manufacture of micro or nanoparticles such as the amount of surfactant used, the type of encapsulated active 
ingredient, and attractive or repulsive attractions between particles $[15,16]$. Previous research conducted by Sukmawati et al. (2017) showed that the release of doxorubicin and PGV-1 was influenced by the concentration of the chitosan matrix used in the manufacture of particle [16]. Saharan et al. (2015) also stated that the release of glipizide from microparticles with a poly-lactic acid (PLA) matrix reduced with the increasing polymer concentration in the manufacture of glipizide microparticles [15]. The release of the active substance from beetroot microparticles will affect the antioxidant activity of the microparticle; hence it is also necessary to evaluate the antioxidant activity of microparticle containing beetroot extract. In this study, we investigated the effect of EC concentration used in microparticles preparation toward the stability of betanin in beetroot MP, release profile of the active substances and their antioxidant activity.

\section{MATERIALS AND METHODS}

\section{Materials}

Materials used in this research were beetroot (Beta vulgaris. Linn) obtained from local market at Boyolali, Central Java, Indonesia, citric acid, ethyl cellulose (EC), Polyvinyl Alcohol (PVA), dichloromethane, betanin as standard for calibration curve, 2,2-diphenyl-1picrylhydrazyl (DPPH) and distilled water. All the chemical in this research were obtained from Sigma Aldrich.

\section{Preparation of beetroot extract}

A $200 \mathrm{~g}$ of peeled and clean beetroot was cut into smaller sizes and mashed using a blender with $200 \mathrm{ml}$ of $1 \%$ citric acid. The beetroot juice obtained then separated from the pulp using a clean cotton cloth and dried using a freeze dryer for $4 \mathrm{~d}$. The obtained beetroot powder from this process was stored in the refrigerator and ready for microparticle preparation.

\section{Microparticle preparation}

Microparticles were made by varying the concentration of ethyl cellulose (EC) as a matrix with a concentration of $5-20 \% \mathrm{w} / \mathrm{v}$ in organic phase using the emulsification method. A $500 \mathrm{mg}$ of EC was dissolved in 10, 5 and $2.5 \mathrm{ml}$ of dichloromethane (DCM) using ultraturax to obtain EC solutions with concentrations of 5, 10 and $20 \% w / v$, respectively. A $250 \mathrm{mg}$ of beetroot powder was dissolved in $1 \mathrm{ml}$ of distilled water and mixed in the EC solution until homogeneous by stirring at $16000 \mathrm{rpm}$ for $3 \mathrm{~min}$. The mixture was then dispersed in $50 \mathrm{ml}$ of $0.5 \%$ polyvinyl alcohol (PVA) solution and continued with stirring using ultraturax 16000 rpm for $3 \mathrm{~min}$ until an emulsion formed. The formation of microparticles was carried out by evaporating the DCM under a fume hood for $24 \mathrm{~h}$ by stirring continuously with a magnetic stirrer at a speed of $600 \mathrm{rpm}$. The particles formed were separated by centrifugation at a speed of $3000 \mathrm{rpm}$. The formed particles were washed using $5 \mathrm{ml}$ of distilled water three times to remove the unencapsulated beetroot extract. The washed microparticles were then dispersed in $3 \mathrm{ml}$ of distilled water and dried using a freeze dryer. The dried microparticles were stored in the refrigerator in a dark glass container.

\section{Microparticles characterization and active substance entrapment}

Characterization of the physical properties of the microparticles was carried out by observing the shape and size of the microparticles (MP) using a scanning electron microscope (SEM), zeta potential and encapsulation efficiency (EE). Observation of particle shape with SEM (Jeol J5M T300) was carried out by taking pictures of microparticles that had been coated with gold under vacuum for 5 min. The coated sample is placed in the sample chamber and bombarded with electrons. The microparticle images were then analysed for their particle size using the ImageJ. Zeta potential of microparticles was measured in dispersed particles in $10 \mathrm{ml}$ of distilled water. The zeta potential of the microparticles was measured using the Horiba Scientific SZ 100 Particle Size Analyzer (PSA).

Entrapment of betanin in microparticles was determined by the direct method using betanin as a standard calibration curve. A total of $100 \mathrm{mg}$ of EC microparticles containing beetroot extract was dissolved in $1 \mathrm{ml}$ of
DCM, then $4 \mathrm{ml}$ of distilled water was added to extract the beetroot extract and shaken. The aqueous phase on the top was taken, and absorbance was measured using a Spectrophotometer UV-Vis (Genesis $10 \mathrm{~S}$ ) at $532 \mathrm{~nm}$. The content of the encapsulated active substance was calculated using betanin as standard with a calibration curve $\mathrm{Y}=$ $0.2055 \mathrm{x}-0.0325$. The encapsulation efficiency (EE) and drug loading (DL) of betanin in microparticles were calculated using equations 1 and 2 .

$$
\begin{aligned}
\operatorname{EE}(\%) & =\frac{\text { amount of betanin in microparticles }}{\text { amount of extract used in microparticles preparation }} \times 100 \% \text {. . eq. [1] } \\
\text { DL }\left(\% \frac{w}{w}\right) & =\frac{\text { amount of betanin in microparticles }}{\text { amount of sample microparticle }} \times 100 \% \ldots \ldots \ldots \ldots \ldots \ldots \ldots . . . . \text { eq. [2] }
\end{aligned}
$$

\section{Evaluation of betanin stability in microparticles}

A $100 \mathrm{mg}$ of microparticles from each concentration of EC matrix (5\%, $10 \%$, and $20 \%$ ) were weighed and stored in a climatic chamber with temperature $40 \pm 2{ }^{\circ} \mathrm{C}$ and relative humidity $75 \% \pm 5 \%$ for $28 \mathrm{~d}$. The identical condition was done for the $50 \mathrm{mg}$ beetroot dry powder. The betanin concentrations in microparticles and beetroot extract were monitored at the beginning of experiments (day 0) until day 28 with 7 $d$ intervals of sampling. The concentration of betanin in microparticles were determined periodically using the similar method to determine drug loading (DL). The betanin in beetroot extract powder was determined by dissolving the extract in $4 \mathrm{ml}$ of distilled water and then filtered using a membrane filter to separate the aqueous phase and the precipitate. The absorbance of the aqueous phase then was measured using the Spectrophotometer UV-Vis (GENESYS 10S) at $532 \mathrm{~nm}$. The betanin concentration was calculated using the standard curve of betanin $(Y=0.2055 \mathrm{x}-0.0325)$. The percentage of reduced betanin level during storage was calculated by compared the betanin level in microparticle and beetroot extract at day 28 with the level of betanin at the beginning of the experiment (day 0 ).

\section{Evaluation of betanin release from the microparticle}

The release profile of the active substance from the microparticles was evaluated by the dissolution method using a shaking thermostatic water bath (Julabo SW22) to maintain the temperature at $37 \pm 0.5{ }^{\circ} \mathrm{C}$. A total of $500 \mathrm{mg}$ of microparticles were dispersed in $5 \mathrm{ml}$ of distilled water using a glass tube and placed in a shaking thermostatic water bath at a speed of $150 \mathrm{rpm}$. The amount of betanin released was measured by taking 5 $\mathrm{ml}$ dissolution medium periodically from 2 to $180 \mathrm{~min}$. The dissolution medium was replaced with a new medium at the same volume $(5 \mathrm{ml})$ at each sampling point. The sample of dissolution medium at each time point was centrifuged and filtered to precipitate the particles. The concentration of the betanin released was measured using UV-Vis Genesis 10S Spectrophotometer at $532 \mathrm{~nm}$. The concentration of the active substance released in the medium was calculated using betanin calibration curve $(Y=0.2055 x-0.0325)$. The release profile of the active substance from microparticles was plotted using kinetic release of order $0,1,2$ and Higuchi equations to determine the mechanism of release and the rate of drug release.

\section{Evaluation of antioxidant activity in microparticle}

The antioxidant activity was evaluated using the 2,2-diphenyl-1picrylhydrazyl (DPPH) method. Antioxidant activity testing was carried out on microparticle containing beetroot extract. A testing microparticles were dissolved using methanol to give concentration of $10 \mathrm{mg} / \mathrm{ml}$. A series of concentration of microparticles solution was obtained by diluting the $10 \mathrm{mg} / \mathrm{ml}$ of microparticle solution using methanol to give concentration of $0.625 \mathrm{mg} / \mathrm{ml}-10 \mathrm{mg} / \mathrm{ml}$. A $100 \mu \mathrm{l}$ of microparticle solution from the series of concentration then was pipetted into a 96 well plate and mixed with $100 \mu \mathrm{l}$ of 0.05 $\mathrm{mg} / \mathrm{ml}$ DPPH solution. A series of control solution was provided in the same plate i.e. $100 \mu \mathrm{l}$ of microparticle solution with $100 \mu \mathrm{l}$ of methanol, $100 \mu \mathrm{l}$ of $0.05 \mathrm{mg} / \mathrm{ml}$ DPPH with $100 \mu \mathrm{l}$ of methanol and $100 \mu \mathrm{l}$ of methanol. The plate was then covered with aluminium foil and incubated at $37^{\circ} \mathrm{C}$ for $30 \mathrm{~min}$. The remaining amount of DPPH was measured using an Elisa reader (Thermo Scientific Multiscan EX) at $490 \mathrm{~nm}$. The remaining amount of DPPH in the solution was calculated as DPPH scavenged activity (\%) as stated in equation [3].

$$
\text { DPPH scavenged activity (\%) = }
$$

$\frac{\text { (abs.microparticle+DPPH)-(abs.microparticle+methanol) }}{\text { (abs.DDPH+methanol)-(abs.methanol) }} \times 100 \%$.

$$
\text { .....eq. [3] }
$$




\section{RESULTS AND DISCUSSION}

\section{Microparticle preparation and characterisation}

The emulsification method was used to produce microparticles containing beetroot extract based on the properties of the EC and beetroot extract. The EC has a high solubility in organic solvents, while the beetroot extract was soluble in water. In this study, PVA was used as an emulsifier. The yield of microparticles produced from EC as a matrix with concentrations of 5,10 and $20 \% \mathrm{w} / v$ ranged from $63-65 \%$.
The shape of the resulting microparticles was evaluated using a scanning electron microscope (SEM) at a magnification of 500 times. The SEM results show that the resulting particles are not spherical in shape and there are several cavities in the microparticles caused by the rapid evaporation of organic solvents from the microparticles.

The morphology of the microparticles produced at various concentrations of the EC matrix can be seen in fig. 1.

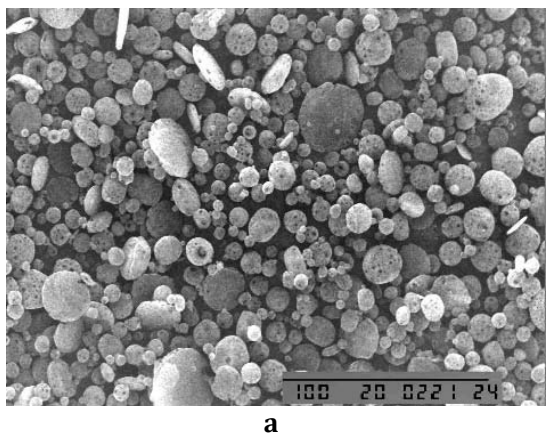

Fig. 1: Microparticles containing beetroot extract using concentration of EC 5\% (a), $10 \%$ (b) and $20 \%$ (c)

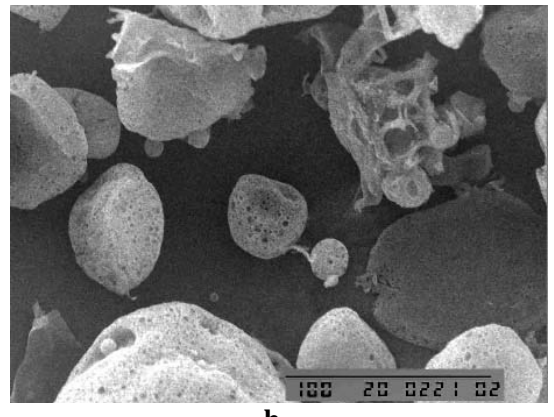

b

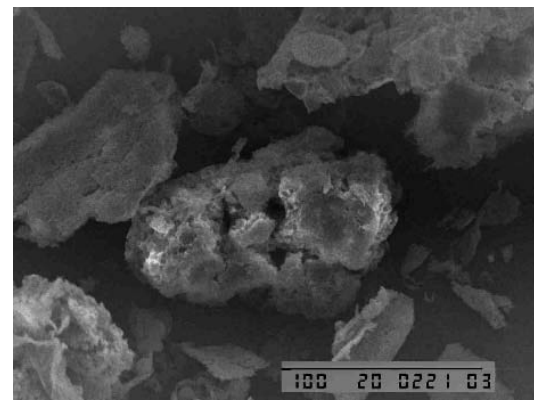

The size of particles evaluated using Image revealed that the larger particles were produced related to the increasing concentration of the EC polymer during the manufacture of microparticles (table 1). The increasing the viscosity in the organic phase during microparticle preparation induce the viscous solution which more resist to form small droplet, therefore, the bigger oil droplets were formed, resulting in larger particle size in the high concentration of polymer $[17,18]$.

Table 1: Particle size of microparticle containing beetroot extract using EC $5 \%, 10 \%$ and $20 \%$ as a matrix

\begin{tabular}{lll}
\hline EC concentration $(\%)$ & Average of particle diameter $(\boldsymbol{\mu m}) *$ & Range of particle mode $(\boldsymbol{\mu m})$ \\
\hline 5 & $5.10 \pm 0.61$ & $4.12-6.12$ \\
10 & $31.39 \pm 7.34$ & $18.20-43.20$ \\
20 & $40.90 \pm 10.64$ & $20.56-58.56$ \\
\hline
\end{tabular}

*values represent mean $\pm \mathrm{SD}(\mathrm{n}=3)$

The evaluation of the zeta potential of the microparticles was carried out to determine the stability of the microparticles in the dispersion system. This information will be useful when microparticles will be further formulated in cosmetic preparations. Particles with a zeta potential value of $\pm 30 \mathrm{mV}$ are considered more stable in a dispersion system [19]. The zeta potential of microparticles was varies depend on the concentration of EC (table 2). The microparticle using 5\% EC has a zeta potential above $30 \mathrm{mV}$, which indicated that the particles have better stability in the dispersion system. The higher zeta potential (above $\pm 30 \mathrm{mV}$ ) of microparticles using 5\% EC concentration of $5 \%$ was associated with small particle size compared to EC concentrations of 10 and $20 \%$. Hence, it can be concluded that small particle size has better stability in the dispersion system.

Table 2: Zeta potential of microparticle containing beetroot extract with EC concentration of $5 \%, 10 \%$ and $20 \%$

\begin{tabular}{ll}
\hline EC concentration & Zeta potential $(\mathbf{m V})^{*}$ \\
\hline $5 \%$ & $-32.4 \pm 1.64$ \\
$10 \%$ & $-8.1 \pm 0.6$ \\
$20 \%$ & $-26.8 \pm 1.0$ \\
\hline
\end{tabular}

*values represent mean $\pm \mathrm{SD}(\mathrm{n}=3)$

The entrapment of the active substance of beetroot extract in the EC microparticle was expressed as encapsulation efficiency (EE) and drug loading (DL). The EE value indicates the effectiveness of the active ingredient absorption within the microparticles, while the DL indicates the amount of the active ingredient (betanin) in a 100 gram of microparticles. The results showed that the entrapment of beetroot extract in the EC microparticles improved along with the increasing of EC polymer in the organic phase during the manufacturing of microparticles (table 3). A high concentration of EC polymer could enhance the speed of microparticle formation, as a result, the absorption of the active substance also occurs more efficiently [20]. In addition, the increasing in the concentration of the EC polymer in organic phase lead to the higher binding capacity of the active substance on the EC, as a result the beetroot extract was more attached to the polymer [21]. The high polymer concentration induced a higher value of EE was also found in the research carried out by Ambikar and Bhosale (2021) [22]. The effect of various EC concentration on the drug loading was statistically analysed using ANOVA test and showed a significant difference ( $p$-value $<0.05)$. It was indicated that higher concentration of EC concentration in organic phase during manufacturing of microparticles lead to the significant increasing of drug loading of produced microparticles.

Table 3: The entrapment efficiency (EE) and drug loading (DL) of microparticle containing beetroot extract using EC 5\%, 10\% and $20 \% *$

\begin{tabular}{lll}
\hline ECconcentration & EE $(\%)^{* *}$ & DL $(\% \boldsymbol{w} / \boldsymbol{w})^{* *}$ \\
\hline $5 \%$ & $11.49 \pm 0.49$ & $5.74 \pm 0.25$ \\
$10 \%$ & $18.03 \pm 0.14$ & $9.02 \pm 0.07$ \\
$20 \%$ & $26.57 \pm 0.49$ & $13.28 \pm 0.24$ \\
\hline
\end{tabular}

*amount of active substance entrapped in microparticle calculated as betanin, ${ }^{* *}$ values represent mean \pm SD $(n=3)$ 


\section{Betanin stability in microparticle}

Stability of betanin was evaluated in microparticles and dry beetroot extract for $28 \mathrm{~d}$ at condition $40 \pm 2{ }^{\circ} \mathrm{C}$ and relative humidity (RH) of $75 \% \pm 5 \%$. The level of betanin in microparticles and dry extract was evaluated at the beginning of the experiment (day 0) until day $28^{\text {th }}$. The level of betanin in all formulas of microparticles and dry beetroot extract was decreased gradually from day $7^{\text {th }}$ to day $28^{\text {th }}$. The percentage reduction of betanin level was calculated based on the level of betanin at day 0 . fig. 2 shown the highest reduction of betanin level was revealed in dry extract of beetroot (37.5\%).

This showed that the betanin in the form of microparticles was more stable than in the form of dry beetroot extract.
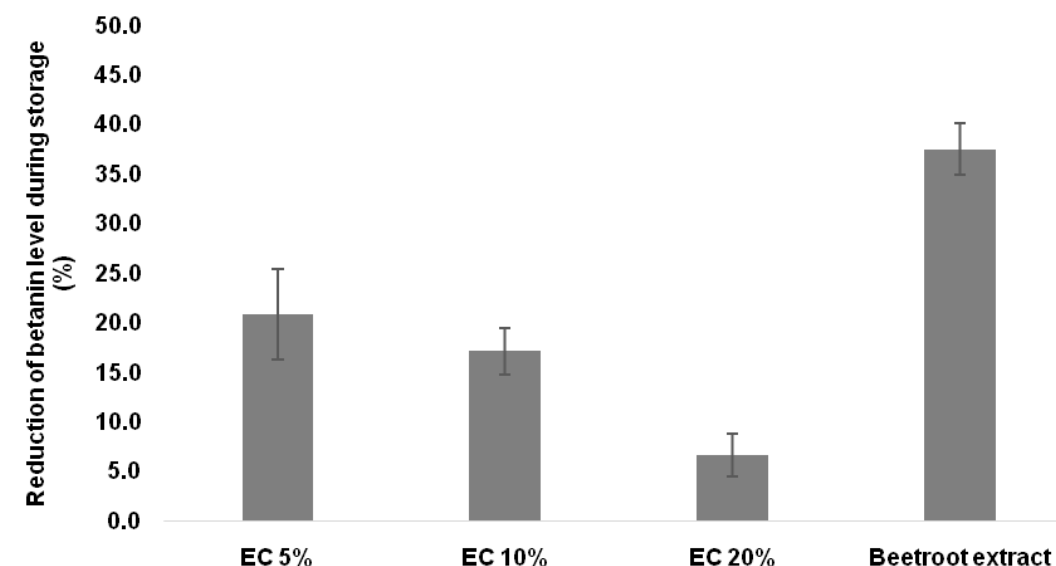

Fig. 2: Percentage reduction of betanin level during $28 \mathrm{~d}$ storage in microparticle EC $5 \%, 10 \%, 20 \%$ and dry beetroot extract (at $40 \pm 2{ }^{\circ} \mathrm{C}$, RH $75 \% \pm 5 \%)$. Values represent mean \pm SD $(n=3)$

The reduction level of betanin in EC microparticles was influenced by the EC concentration as statistically analysed using ANOVA $(\mathrm{p}<0.05)$. The protection of active substance from degradation was increased related to the increasing concentration EC as a matrix of microparticle. The paired t-test for the percentage of reduced level of betanin between microparticle using EC 5\% and 10\% showed no significant difference $(p>0.05)$. It was suggested that the ability of EC polymer as a matrix to protect encapsulated active substance was similar in the concentration of EC $5 \%$ and $10 \%$. However, the t-test for reduced level betanin between microparticle using EC $20 \%$ with microparticle using EC $5 \%$ and $10 \%$ revealed the p-value $<0.05$. It was shown that EC $20 \%$ had significant better protection to maintain stability of betanin in microparticle compared to microparticle using EC 5 and 10\%. It could be assumed that the microparticles using EC $20 \%$ had the best protection to maintain stability of encapsulated betanin as the higher concentration of polymer might related to the increasing thickness of entrapping wall in the microparticle.

\section{Release profile of betanin from microparticle}

The amount of betanin released from the microparticle preparation was evaluated up to $180 \mathrm{~min}$. The results showed that the most rapid released of betanin was found at $5 \%$ EC concentration where at 90 min the active ingredient released had reached around $90 \%$ (fig. 3) followed by microparticles using EC $20 \%$ and EC $10 \%$.

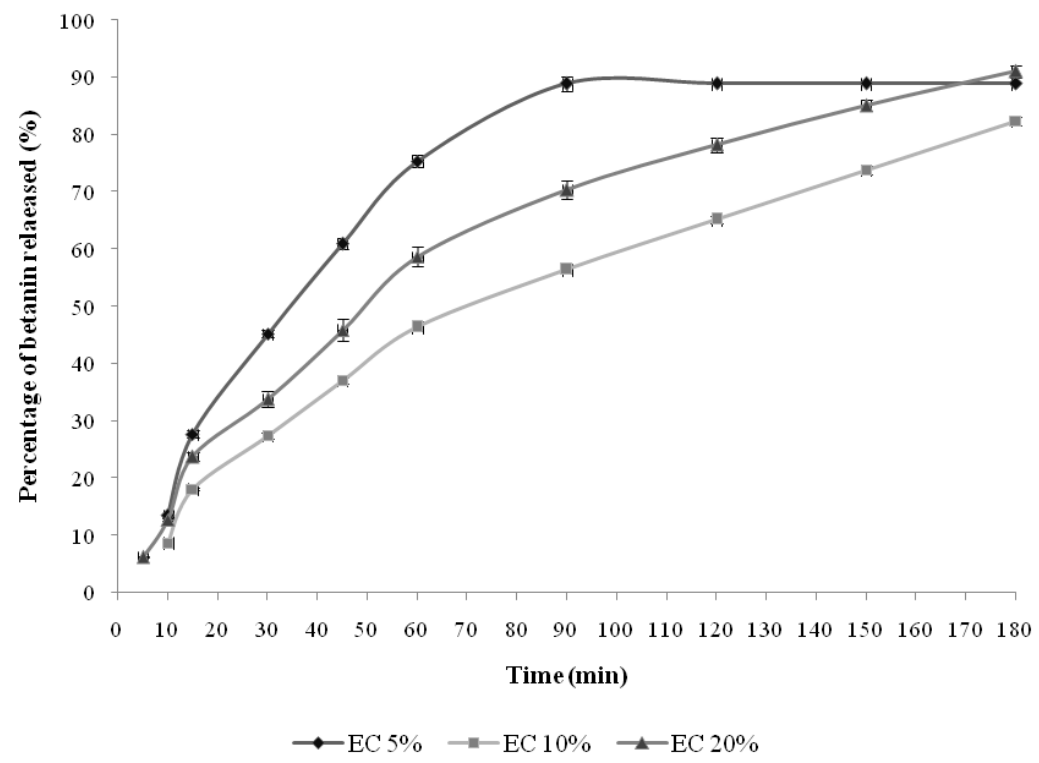

Fig. 3: Cumulative of betanin released from microparticles containing beetroot extract using EC 5, 10 and $20 \%$ in water as a dissolution medium for $180 \mathrm{~min}$ at $37^{\circ} \mathrm{C}$ (values represent mean $\pm \mathrm{SD}, \mathrm{n}=3$ )

In order to determine the kinetics of the release of the active substance from the microparticles, a plotting of the model was carried out using the equations for zero, first, second-order release as well as Higuchi model. Based on the $\mathrm{R}^{2}$ value, it was found that the 
release of betanin from EC microparticles was fit into the Higuchi model (table 4). Hence, it could be said that the mechanism release of the betanin from the EC microparticles was through diffusion process.

Table 4: The $\mathrm{R}^{2}$ value for the release profile of betanin from microparticle using EC 5,10 and $20 \%$. The $\mathrm{R}^{2}$ were obtained by plotting using zero, first, second order and higuchi model $(n=3)$

\begin{tabular}{llll}
\hline EC concentration (\%) & $\mathbf{R}^{\mathbf{2}}$ & & \\
\cline { 2 - 4 } & Zero-order & First-order & Second-order \\
\hline 5 & $0.938 \pm 0.007$ & $0.773 \pm 0.022$ & $0.555 \pm 0.035$ \\
10 & $0.954 \pm 0.001$ & $0.759 \pm 0.003$ & $0.481 \pm 0.003$ \\
20 & $0.910 \pm 0.009$ & $0.684 \pm 0.006$ & $0.393 \pm 0.003$ \\
\hline
\end{tabular}

*values represent mean $\pm \mathrm{SD}(\mathrm{n}=3)$

The Higuchi equation was then used to evaluate the rate of release of betanin from the microparticles. The results showed that the largest release rate was found in microparticles with an EC concentration of $20 \%$ (table 5). This result was in contrast to the research conducted by Maji et al.(2012) where the rate of release of the active compound becomes slower at higher polymer concentrations [23]. This could be due to the presence of more pores in the microparticles using EC concentration of $20 \%$, as consequences the drug release could not be controlled properly by the matrix.

Table 5: Rate of release of betanin from microparticle containing beet root extract using EC 5, 10 and $20 \%(n=3)$

\begin{tabular}{ll}
\hline EC concentration $(\%)$ & Release rate of betanin $(\mathbf{m g} / \mathbf{m i n})^{*}$ \\
\hline 5 & $7.434 \pm 0,102$ \\
10 & $6.946 \pm 0,067$ \\
20 & $7.780 \pm 0,137$ \\
\hline
\end{tabular}

*values represent mean \pm SD $(n=3)$

The ANOVA statistical analysis was done for the release rate of betanin from microparticle ECcontaining beetroot extract. The result showed the p-value $<0.05$ indicated that the variation in EC concentration could influence the betanin release rate from the microparticles. The release rate of betanin from microparticles using EC $20 \%$ was the fastest among the other formulas.

\section{Antioxidant activity of microparticle}

The antioxidant activity of EC microparticles containing beetroot extract was evaluated using DPPH (2,2-diphenyl-1-picrylhydrazyl), a free radical molecule. The ability of beetroot extract microparticles in reducing DPPH free radicals was expressed as antioxidant activity. The reduction of $\mathrm{DPPH}$ free radical activity by antioxidant compounds was indicated by a change in DPPH colour from purple to yellow. The antioxidant activity of beetroot extract microparticles was evaluated by measuring the amount of DPPH that did not change with the addition of beetroot extract microparticles and expressed as effective concentration $50\left(\mathrm{EC}_{50}\right)$ or the concentration required to produce $50 \%$ antioxidant effect [24]. The results showed that beetroot extract microparticles using EC 20\% had the highest antioxidant activity compared to other microparticles as seen from the lowest $\mathrm{EC}_{50}$ value (table 6). This phenomenon related to the presence of the largest active ingredient of beetroot extract microparticles using EC concentration of $20 \%$.

Table 6: Effective concentration $50\left(\mathrm{EC}_{50}\right)$ of ethyl cellulose microparticle containing beetroot extract using DPPH

\begin{tabular}{ll}
\hline EC concentration $(\%)$ & EC $_{\mathbf{5 0}}(\mathbf{m g} / \mathbf{m l}) *$ \\
\hline 5 & $12.22 \pm 1.464$ \\
10 & $10.48 \pm 0.554$ \\
20 & $6.306 \pm 0.137$ \\
\hline
\end{tabular}

*values represent mean \pm SD $(n=3)$
The ANOVA statistical analysis for $\mathrm{EC}_{50}$ showed that there were significant differences in antioxidant activity at various concentrations of the EC matrix $(\mathrm{P}<0.05)$, however, the antioxidant activity in microparticles using EC 5\% and 10\% showed no significant difference $(\mathrm{p}>0.05)$.

\section{CONCLUSION}

A microparticle system using ethyl cellulose (EC) polymer as a matrix was successfully produced and had the ability to retain the stability of betanin as the active substance in beetroot extract. The higher the concentration of the EC polymer in organic phase during microparticles preparation induced larger particle size and higher entrapment of active substance. Betanin in microparticles was more stable than the dry beetroot extract and the EC $20 \%$ as a matrix showed the best protection to retain the stability of betanin. The release profile of betanin from microparticles followed the Higuchi model and the rate of release was influenced by the concentration of EC in microparticle production. The EC microparticles showed the antioxidant activity with the highest antioxidant shown in the microparticle containing beetroot extract using EC 20\% as a matrix.

\section{ACKNOWLEDGEMENT}

The authors would like to thanks to Universitas Muhammadiyah Surakarta, Indonesia for funding and giving laboratories facilities for this research. We also thanks to Balai Konservasi Borobudur, Magelang, Indonesia, to provide Scanning Electron Microscope (SEM) facilities for particles imaging.

\section{FUNDING}

This research was funded through research grant scheme: Hibah Integrasi Tridharma (HIT) provided by Universitas Muhammadiyah Surakarta, Indonesia.

\section{AUTHORS CONTRIBUTIONS}

Anita Sukmawati has a contribution for the general research plan and prepared manuscript; Setyo Nurwaini and Umi Budi Rahayu has contributed to supervised lab work and support manuscript preparation; Apriliana P. C. Widawan, Anita Safitri and Novia W. N. Astria was contributed to data collection and research report.

\section{CONFLICT OF INTERESTS}

There is no conflict of interest.

\section{REFERENCES}

1. Canadanovic Brunet JM, Savatovic SS, Cetkovic GS, Vulic JJ, Djilas SM, Markov SL, Cvetkovic DD. Antioxidant and antimicrobial activities of beetroot pomace extracts. Czech J Food Sci. 2011;29(6):575-85. doi: 10.17221/210/2010-CJFS.

2. Nemzer B, Pietrzkowski Z, Sporna A, Stalica P, Thresher W, Michałowski T, Wybraniec S. Betalainic and nutritional profiles of pigment-enriched red beet root (Beta vulgaris L.) dried extracts.

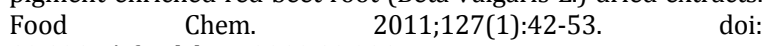
10.1016/j.foodchem.2010.12.081.

3. Al-Ismail K, El-Dijani L, Alkhatib H, Saleh M. Effect of microencapsulation of vitamin $\mathrm{C}$ with gum arabic, whey protein isolates and some blends on its stability. J Sci Ind Res (India). 2016 Mar 1;75:176-80. 
4. Handayani MN, Khoerunnisa I, Cakrawati D, Sulastri A. Microencapsulation of dragon fruit [Hylocereus polyrhizus] peel extract using maltodextrin. IOP Conf Ser Mater Sci Eng. 2018;288:1-8.

5. Adeleke OA. Premium ethylcellulose polymer-based architectures at work in drug delivery. Int J Pharm X. 2019;1:100023. doi: 10.1016/j.ijpx.2019.100023.

6. Ma X, Liu Y, Fan L, Yan W. Ethylcellulose particles loaded with $\alpha$-tocopherol for inhibiting thermal oxidation of soybean oil. Carbohydr Polym. 2021;252:117169. doi: 10.1016/j.carbpol.2020.117169.

7. Antigo JLD, Bergamasco RdC, Madrona GS. Effect of $\mathrm{pH}$ on the stability of red beet extract (Beta vulgaris 1.) microcapsules produced by spray drying or freeze-drying. Food Sci Technol. 2018;38(1):72-7. doi: 10.1590/1678457x.34316.

8. Torres RC, Yumang RM G, Jose CK F, Canillo DC P. Microencapsulation of betalain from Philippine Beta vulgaris as stable colorant powder. Open J Food Nutr Res. 2019:17-25. doi: 10.36811/ojfnr.2019.110003

9. Dong F, Wang Y. Encapsulation of vitamin C by A double-layer Zein/chitosan structure with improved. Int J Nanomed Nanosurgery. 2016;2(1):1-7.

10. Rojas J. Chitosan as a potential microencapsulation carrier for ascorbic acid stabilization in heterodisperse systems. Int J Pharm Pharm Sci. 2015;7:69-72.

11. Gurav AS, Sayyad FJ, Gavhane YN, Khakal NN. Development of olmesartan medoxomil-loaded chitosan microparticles: a potential strategy to improve physicochemical and micromeritic properties. Int J Pharm Pharm Sci. 2015;7:324-30.

12. Muhaimin. Study of microparticle preparation by the solvent evaporation method using focused beam reflectance measurement (FBRM); 2013. p. 225. doi: 10.17169/REFUBIUM-10516

13. Mehta RC, Thanoo BC, Deluca PP. Peptide containing microspheres from low molecular weight and hydrophilic poly(d,l-lactide-co-glycolide). J Controlled Release. 1996;41(3):249-57. doi: 10.1016/0168-3659(96)01332-6.

14. Omar Zaki SS, Ibrahim MN, Katas H. Particle size affects concentration-dependent cytotoxicity of chitosan nanoparticles towards mouse hematopoietic stem cells. J Nanotechnol. 2015;2015:1-5. doi: 10.1155/2015/919658.
15. Saharan P, Bhatt DC, Saharan SP, Bahmani K. The study the effect of polymer and surfactant concentration on characteristics of nanoparticle formulations. Pharm Lett. 2015;7:365-71.

16. Sukmawati A, Da'i M, Yuliani R, Anggraeni S, Wahyuningsih D. Characterization of chitosan nanoparticle-containing combination doxorubicin and curcumin analogue. Adv Sci Lett 2017;23:12486-8.

17. Sharma N, Madan P, Lin S. Effect of process and formulation variables on the preparation of parenteral paclitaxel-loaded biodegradable polymeric nanoparticles: A co-surfactant study. Asian J Pharm Sci. 2016;11(3):404-16. doi: 10.1016/j.ajps.2015.09.004

18. Biswas R, Sen KK. Development and characterization of novel herbal formulation (Polymeric microspheres) of syzygium cumini seed extract. Int J App Pharm. 2018;10(5):226-34. doi: 10.22159/ijap.2018v10i5.28624.

19. Mirabedini SM, Dutil I, Farnood RR. Preparation and characterization of ethyl cellulose-based core-shell microcapsules containing plant oils. Colloids Surfaces A: Physicochemical Engineering Aspects. 2012;394:74-84. doi: 10.1016/j.colsurfa.2011.11.028.

20. Yeo Y, Park K. Control of encapsulation efficiency and initial burst in polymeric microparticle systems. Arch Pharm Res. 2004;27(1):1-12. doi: 10.1007/BF02980037, PMID 14969330.

21. Lokhande $A B$, Mishra S, Kulkarni RD, Naik JB. Influence of different viscosity grade ethylcellulose polymers on encapsulation and in vitro release study of drug-loaded nanoparticles. J Pharm Res. 2013;7(5):414-20. doi: 10.1016/j.jopr.2013.04.050.

22. Ambikar RB, Bhosale AV. Development and characterization of diclofenac sodium loaded eudragit RS100 polymeric microsponge incorporated into in situ gel for ophthalmic drug delivery system. Int J Pharm Pharm Sci. 2021;13:63-9.

23. Maji R, Ray S, Das B, Nayak AK. Ethylcellulose microparticles containing metformin $\mathrm{HCl}$ by emulsification-solvent evaporation technique: effect of formulation variables. ISRN Polym Sci. 2012;2012:1-7. doi: 10.5402/2012/801827.

24. Chen Z, Bertin R, Froldi G. EC50 estimation of antioxidant activity in DPPH - assay using several statistical programs. Food Chem. 2013;138(1):414-20. doi: 10.1016/j.foodchem. 2012.11.001, PMID 23265506. 